\title{
Knowledge and Practice of Antenatal Care among Chepang Women from Chitwan, Nepal
}

\author{
Ms. Sunita Shrestha ${ }^{1}$, Ms Rashmi Shrestha ${ }^{1}$, Mr. Tej Kumar Shrestha ${ }^{2 *}$, Prof. Dr. Erene \\ Shrestha $^{3}$, Prof. Dr. Sarala Joshi ${ }^{4}$, Mr. Ganesh Paudel ${ }^{5}$ \\ ${ }^{1}$ Lecturer, Om Health Campus, Kathmandu, Nepal \\ ${ }^{2}$ Lecturer, Khwopa College, Dekocha, Bhaktapur, Nepal \\ ${ }^{3}$ Professor, Padma Kanya Campus, Kathmandu, Nepal \\ ${ }^{4}$ Principal, Om Health Campus, Kathmandu, Nepal \\ ${ }^{5}$ Assistant Planning Officer, Department of Forest, Babarmahal, Kathmandu
}

*Corresponding Author: Tej Kumar Shrestha, Lecturer, Khwopa College, Dekocha, Bhaktapur, Nepal, Email: tejthaiva@hotmail.com

\begin{abstract}
Introduction: Chepang are marginalized ethnic people deprived of basic services with poor access to health facilities which makes them vulnerable particularly Chepang women during pregnancy.

Methods: This research was conducted in Kalika Municipality of Chitwan district, among reproductive age women of Chepang community with an objective to understand the knowledge and practice of antenatal care.

Results: This study shows that their knowledge and practice is directly associated with their education level viz. the number of children, visits to health posts, etc increase and decrease with their education level.

Conclusion: With very few populations of this indigenous community scattered in various districts of Nepal, it is important to help them to gain education which can help to reduce the mortality rate of mother and baby and live healthy.
\end{abstract}

Keywords: Chepang, antenatal care, reproductive age, pregnancy.

\section{INTRODUCTION}

The Chepang are locally called "Praja" meaning citizen that are Tibeto-Burman indigenous groups in Nepal. The Chepang reside in the steeper slope of the Mahabharat range at elevation of 500 to 1200 mean sea levels (Bista, 1967). They are extremely marginalized ethnic people with own ethnic language. They are also characterized by linguistic, cultural, religious, and economic commonalities (Sharma, 2011). They worship the nature which provides them food, cloth and shelter for their wellbeing. The Chepang community with a population of 68,399 constitutes $(0.25 \%)$ geographically, 1,655 in urban area and 66,744 in rural area (CBS, 2011). More than $98 \%$ of the Chepang live in Chitwan, Makwanpur, Dhading and Gorkha districts and among them, $42 \%$ of total Chepang population live in Chitwan alone (NCA, 2009). More than three quarter of the Chepang community are illiterate and although the literacy rate in Nepali is increasing $54.1 \%$ of the population is literate, only one percent of the Chepang know how to read and write ( UNRCHCO, 2012).

Antenatal care is very poor among the low socioeconiomic pregnant women because of their negative life events and these group of women rarely seek for the prenatal care ( Maquis \& Butler,2001) . It is a periodic and regular supervision including examination and advice of a woman during pregnancy that includes health education, counselling, screening and treatment for better and positive outcome of both mother and baby. (Di Mario et al., 2005). Antenatal care is "a comprehensive antepartum care program that involves a coordinated approach to medical care and psychological support that optimally begins before conception and extends throughout the antenatal care". Early and timely antenatal care reduces the chances of prematurity, intrauterine growth retardation, congenital deformed newborn and prompt treatment of any complications during antenatal periods (Fraser, 2013). Supplements of $400 \mathrm{mg}$ of folic acid per 
day at least 4 weeks before pregnancy and 28 days after the conception can reduce the probability of birth defect, particularly neural tube defect (Berry et al.,1999).World Health Organization (WHO) in November 2016 recommended the number of antenatal visit should be at least 8 times during pregnancy, considering that minimum eight contact of antenatal care reduces perinatal mortality up to $8 / 1000$ (0.8\%) birth (WHO, 2016) but Government of Nepal is still focused on four antenatal visit.

Chepang community is deprived of the basic human needs such as food and shelter. Low literacy rate with approximately $23 \%$ of the total population, little knowledge on health issues such as Safe Motherhood and early marriage has made them more prone to poor health. Data shows that only $40 \%$ Chepang have access to primary health care services while only $25 \%$ receives basic health services from the health posts (NCA, 2009). This study seeks to assess the condition of antenatal care among the reproductive age women in Chepang community and determine the knowledge and practices of antenatal care in this target group.

Approximately entire world's (99\%) maternal death is recorded in developing countries, making maternal mortality the health statistics with largest disparity between developed and developing countries (WHO, 2011). In global context, each year there are at least 3.2 million still born babies, 4 million neonatal deaths and more than 0.5 million maternal deaths. A key reason for this situation is the gap between what is needed and what exists in terms of skills and geographical availability of human resources at local, national and international levels (WHO, 2011). A study conducted in 2000 in Africa, showed that annually 150,000 African women died due to pregnancy and child bearing complications. The main cause of this problem was delay in arrival to hospital, low quality hospital and lack of Traditional Birth Attendants (Luck, 2000). In sub-Saharan Africa, around 900,000 babies die as still birth in last trimester of the pregnancy. It is estimated that two third of the still births are recorded before the onset of labour, antepartum period. Mortality rates remained high in all African countries more than $22 / 1000(2.2 \%)$ births (Lincetto, WHO). The maternal mortality in the third world countries like Ethiopia has $673 / 100,000(0.673 \%)$ and infant mortality rate of 77/1000 (7.7\%) in 2005 (EDHS, 2005).
According to trends of Maternal Mortality Ratio (MMR) in Nepal there was 281/100,000 (0.28\%) in 2006 that reduced to $170 / 100,000(0.17 \%)$ in 2011 , however it raised to $239 / 100,000(0.239 \%)$ in 2016 and target for 2017 and 2020 are $151 / 100,000(0.15 \%)$ and 127/100,000 (0.127 $\%)$ respectively. Similarly, Neonatal Mortality Rate (NMR) was 33/1000 (3.3\%) live births in 2006 (DHS, 2011) that reduced to $23 / 1000$ (2.3 $\%)$ in $2014,21 / 1000(2.1 \%)$ in 2016 and target for 2017 and 2020 are 17/1000 (1.7\%) and 14/1000 (1.4\%) respectively (NHSP-IP,20162021).

\section{Materials And Methods}

\subsection{Study Site}

This research was conducted in Samfrang, Darbetar, Dogra, Kuwapani villages (formerly Shaktikhor VDC) of Kalika Municipality of Chitwan district. Chitwan district is approximately $110 \mathrm{~km}$ from Kathmandu via road. The study site is situated on the northern part of the Chitwan district which is approximately $30 \mathrm{~km}$ from district headquarter Bharatpur and $17 \mathrm{~km}$ from the East West highway.

\subsection{Data Collection and Analysis}

This research is based on the primary data information collected among the reproductive age women of Chepang community using semi structured questionnaire. Data from field was collected between April 2016 and January 2017. 100 respondents were selected using purposive sampling methods among the target women from the site. Field data were entered using SPSS 20 version for data analysis. Chisquare test was conducted to assess the association between different variables and ANC.

\section{ReSUlts}

This paper solely focuses on the knowledge of the targeted community about antenatal care. Study came up with information regarding knowledge about consultation during pregnancy period, importance of antenatal care, frequency of visits to the health care, types of complication during pregnancy, awareness on anemia and their precautions, restriction and rest during pregnancy and smoking and drinking alcohol effects.

\subsection{Importance of Antenatal Care}

More than half (52\%) of this community did not know the importance of the antenatal care. One third $(31 \%)$ of this group informed that antenatal care would be helpful for monitoring the health of both mother and baby. 10\% told that this 
would maintain and monitor the health condition of mother while $7 \%$ told this would monitor the fetal condition during pregnancy.

\subsection{Number of Children Against Literacy}

Most $(82.34 \%)$ of the literate group of this community had up to 2 children with rest (17.64 $\%)$ 3-5 children. In contrast few $(30.30 \%)$ of the illiterate group had up to 2 children while most $(69.70 \%)$ had either 3-5 (43.95\%) or more than 6 $(25.75 \%)$ children. The association between the literacy and number of children was found significant $(\mathrm{P}=0.000, \mathrm{df}=2, \alpha=0.05)$. This shows that the number of children is dependent on the literacy level viz it is uncovered that illiterate women have more number of children than the literate women.

\subsection{Number of Antenatal Visit Against Literacy}

In regard to the antenatal visit by both literate and illiterate group, more than half of the literate group of targeted community (61.8\%) had more than 4 antenatal visits while only less than one third $(31.8 \%)$ of the illiterate had less than 4 antenatal visit. There was significant association between the literacy and number of antenatal visit $(\mathrm{P}=0.014, \mathrm{df}=3, \alpha=0.05)$. This shows that the number of antenatal visit is dependent on the literacy level which means that literate women have more antenatal visits compared to illiterate women.

\subsection{Complication During Pregnancy}

Table1. Complications, consultation and complication types

\begin{tabular}{|l|l|l|}
\hline $\begin{array}{l}\text { Complication arises } \\
\text { during pregnancy }\end{array}$ & Frequency & Percent \\
\hline Yes & 37 & $37 \%$ \\
\hline No & 63 & $63 \%$ \\
\hline $\begin{array}{l}\text { If yes, consulting person } \\
\text { during complications } \\
\text { (Multiple response) }\end{array}$ & & \\
\hline Local healers & 60 & $59.4 \%$ \\
\hline Families and Friends & 27 & $26.7 \%$ \\
\hline Health personnel & 14 & $13.9 \%$ \\
\hline $\begin{array}{l}\text { Types of complication } \\
\text { faced during pregnancy } \\
\text { (Multiple response) }\end{array}$ & & \\
\hline $\begin{array}{l}\text { Edema on hand, face and } \\
\text { feet }\end{array}$ & 31 & $48.4 \%$ \\
\hline Severe Headache & 21 & $32.8 \%$ \\
\hline Blurred vision & 1 & $1.6 \%$ \\
\hline Per vaginal bleeding & 2 & $3.1 \%$ \\
\hline Seizures & 2 & $3.1 \%$ \\
\hline Loss of fetal movements & 7 & $10.9 \%$ \\
\hline
\end{tabular}

Types of complications and consultations by the respondents during pregnancy period were uncovered in this part of study. About $37 \%$ of the respondents accepted that they suffered from complications while $67 \%$ did not suffer from such complications. Most of those (59.4\%) consulted with the local healers, while $26.7 \%$ and $13.9 \%$ consulted with families, friends and health personnel respectively. Most of complications were edema on hand, face and feet $(48.4 \%)$, severe headache $(32.8 \%)$, loss of fetal movements $(10.9 \%)$. Table 1 has detail on the complications.

\subsection{Number of Antenatal Visit}

$42 \%$ visited to antenatal clinic for 4 to 5 times while only $7 \%$ visited antenatal clinic 1 time. More than one third respondents (39\%) did not visit antennal clinic at all. The mean of the antenatal visit is 2.22 and standard deviation is 1.30 , it means there is little variance in the times of antenatal visit

\subsection{Knowledge on Restricted Activities During Pregnancy}

\begin{tabular}{|l|l|l|}
\hline $\begin{array}{c}\text { Restricted activities during } \\
\text { pregnancy }\end{array}$ & Frequency & \% \\
\hline Yes & 54 & 54 \\
\hline No & 46 & 46 \\
\hline If yes, (Multiple response) & 100 & \\
\hline Avoid heavy lifting & 37 & 43.5 \\
\hline Avoid prolong standing & 12 & 14.1 \\
\hline $\begin{array}{l}\text { Avoid heavy alcohol drinking } \\
\text { and smoking }\end{array}$ & 36 & 42.4 \\
\hline
\end{tabular}

$54 \%$ of the Chepang knew that there are restrictions to some activities during pregnancy. $43.5 \%$ of target group knew that there should be avoidance on heavy lifting, followed by $42.4 \%$ avoiding heavy alcohol drinking and smoking and $14.1 \%$ avoiding prolong standing. $46 \%$ of this group did not know that any restriction should be made during pregnancy.

\subsection{Rest and Sleep According to the Education Level}

\begin{tabular}{|l|l|l|l|}
\hline \multirow{2}{*}{$\begin{array}{c}\text { Education } \\
\text { status }\end{array}$} & \multicolumn{2}{|c|}{$\begin{array}{c}\text { Rest and sleep during } \\
\text { pregnancy }\end{array}$} & \multirow{2}{*}{ Total } \\
\cline { 2 - 3 } & Yes & No & \\
\hline Literate & $19(55 \%)$ & $15(45 \%)$ & 34 \\
\hline Illiterate & $20(30 \%)$ & $46(70 \%)$ & 66 \\
\hline Total & 39 & 61 & 100 \\
\hline
\end{tabular}

Among the literate respondents, more than half of the respondents $(55 \%)$ took rest and sleep against $45 \%$ not taking rest, while $70 \%$ of illiterate did not take any rest with only $30 \%$ taking rest during pregnancy. The more number of literate respondents took rest and sleep during pregnancy thus there was an association between literacy rate and rest during the pregnancy. $(\mathrm{P}=0.01, \mathrm{df}=1, \alpha=0.05)$. 


\subsection{Intake of Iron and Folic acid Against education}

\begin{tabular}{|l|r|r|r|}
\hline \multirow{2}{*}{$\begin{array}{c}\text { Education } \\
\text { level }\end{array}$} & \multicolumn{2}{|c|}{$\begin{array}{l}\text { Intake of Iron and folic acid } \\
\text { (IFA) during pregnancy }\end{array}$} & Total \\
\cline { 2 - 4 } & Yes & No & \\
\hline Literate & $25(73.5 \%)$ & $9(26.5 \%)$ & 34 \\
\hline Illiterate & $26(39.4 \%)$ & $40(60.6 \%)$ & 66 \\
\hline Total & 51 & 49 & 100 \\
\hline
\end{tabular}

The above table shows that almost two third of literate respondents $(73.5 \%)$ consumed IFA during pregnancy while only one third of the illiterate respondents $(39.4 \%)$ consumed IFA. Regarding not taking IFA, only one fourth of literate participants $(26.5 \%)$ did not consumed IFA whereas more than half of illiterate respondents $(60.6 \%)$ did not take IFA during pregnancy. Literate respondents consumed larger percentage of IFA so there is association between literacy and intake of IFA $(\mathrm{P}=0.001, \mathrm{df}=1$, $\alpha=0.05$ ).

3.9. Effects of Smoking and Alcohol Drinking During Pregnancy

\begin{tabular}{|l|l|}
\hline \multicolumn{1}{|c|}{ Effects of smoking \& drinking } & \% \\
\hline Harms health of the baby & 17 \\
\hline Harms health of the mother & 21 \\
\hline No harm to health of baby and mother & 36 \\
\hline Do not know & 26 \\
\hline Total & 100 \\
\hline
\end{tabular}

The table shows that less than one fifth $(17 \%)$ of the respondents responded that smoking and drinking can harm the health of the fetus and about one fifth of the respondents replied that they can harm the health of mother. More than one third of the respondents $(36 \%)$ said they cause no harm to both mother and baby. One quarter of respondents (26\%) did not know about the consequences of the smoking and drinking to during pregnancy.

Delivery of the Chepang women are mostly (78\%) assisted by traditional birth attendants and mother in law. They are also benefitted by significant number of skill birth attendants (20\%) and low (1\%) of Doctors And Midwives While Few (1\%) Of Them Are Not Assisted At All.

Person Assisted During Child Birth

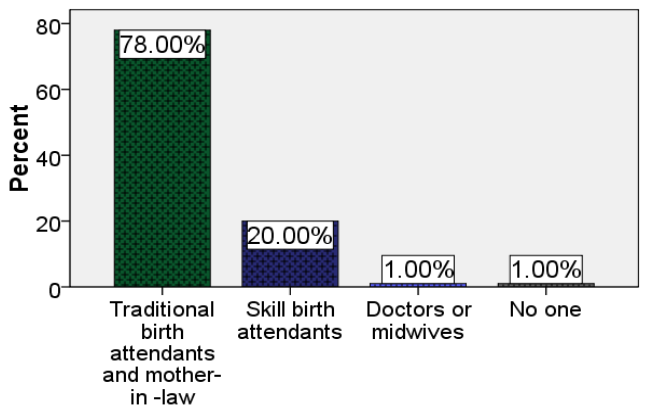

\section{DISCUSSION}

The numbe of Chepang pregnant women with knowledge bout importance of antenatal care is almost half $48 \%$ ) considerably less than Shafqat et al., 2015 suggesting $82.81 \%$ of women are aware of antenatal care. Chepang women knew that the antenatal care would be helpful for both mother and baby. Literacy was found to be significant factor associated with number of birth. Illiterate Chepang women have up to 6 children compared to the literate women having 2 children. Research shows that women under high school level has average of 2.56 birth while those who completed high school and appeared college has only 1.88 and 1.99 birth respectively (Wetzstein, 2011). Number of antenatal visit was also significantly associated with the literacy level and thus literate women had more antenatal visits compared to illiterate women. Considerably few number of Chepang's knew and suffered with complications during pregnancy. It is to be notable that the complications for that community would be either with high risk or the death. This is due to their lack of awareness and education level who neglected low complications during pregnancy. Most $(86 \%)$ of them consulted still consulted with the local healers and their close ones, while only $14 \%$ consult with the health personnel. Literacy was also the significant factors for restriction activities during the pregnancy where almost half of the target women were not aware about the restrictions and $70 \%$ of illiterate women avoided taking rest during pregnancy.

This can be one of the crucial issues which can harm pregnant women and their baby during birth. Similarly, significant women from this community confirmed any harms to mother and baby due to smoking and drinking during pregnancy, which can affect negatively to this community due to lack of their understanding this finding is very similar to alcohol used during pregnancy in safe level is uncertain teratogenic risk on fetus while heavy binge drinking can harm the fetus (Gladstone et al.,1996). NMCTH report indicates that $87 \%$ of the pregnant mother in Nepal attends antenatal visits more than 4 times which in contrast is seen in the case of Chepang women. There is relation between distance of the available facilities and the NMCTH report shows that women far away more than $6 \mathrm{~km}$ are less likely to visit antenatal care. Chepang women are mostly assisted by traditional birth attendants and mother in law with only $20 \%$ assisted by skill birth attendants and only $1 \%$ by doctors or midwives. This study 
is very similar to the study conducted among the socio-demographic factors associated with home delivery assisted by untrained traditional birth attendants in rural Bangladesh in 2013, where 795 of the women have delivered at home by untrained traditional birth attendants (Choudhary et al., 2013)

\section{CONCLUSION}

To conclude this research finding shows that poverty, high illiteracy, inaccessible to the health centers, traditional culture and practices are the main reason for the incidents of child and maternal mortality rate. Study also shows an association between education and their practices related to ANC in this community. Education for this target group can be very much helpful for the protection of mother and baby and thus reduce the mortality rate of mother and baby that will be one of the important tools to achieve the sustainable development goal and Government of Nepal.

\section{REFERENCES}

[1] Berry RJ,Li Z, Ericson JD,Li S, Moore CA, Wang H,Mulinare J,Zhao P,Wong Lc, Gindler J,Hong S,CorreaA. (1999). Prevention of neural tube defect with folic acid in China.New England Journal of Medicine 341( 20):14851490.[PudMed].

[2] Bista, D. B. (1967). People of Nepal. Kathmandu: Ratna Pustak Bhandar.

[3] Cetral Bureau of Statistics (2011). Government of Nepal, National Planning Commission Secretariat, Central Bureau of Statistics.

[4] UNRHCO (2012). Chepang's struggle for survival: views from Makwanpur and Chitwan District, United Nation Resident and Humanitarian coordinator's Office, Issue 47.

[5] Choudhary A.H., Hasan M, Ahmed S, Darwin C, Hasan MS and Haque R. (2013). Sociodemographic factors Associated with home delivery assisted by untrained traditional birth attendant in Rural Bangladesh, American Journal of Public Health Research, Vol.1 no. 8, 226-230.

[6] Di Mario S, Basevi V, Gori G, Spettoli D. (2005). What is the effectiveness of antenatal care? (Supplement), WHO Regional Office for Europe (Health Evidence Network report) 2005.retrived from www.euro.who.int?_data/ asset/pdf_file.

[7] Fraser M.R. (2013). Bringing it all together: effective maternal and child health practice as a means to improve public health. Matern Child Health. 17:767-75.

[8] Gladstone J, Nulman I, Koren G. (1996). Reproductive risk of binge drinking during pregnancy. Reproductive toxicology 10(1):3-13. [PudMed]

[9] Hajarika, I. (2009). Women's Reproductive Health in Slum Populations in India. Bulletin of the New York Academy of Medicine, 87.

[10] Luck, M. (2000). Safe Motherhood Intervention Studies in Africa. East African Medical Journal, 77.

[11] Marquis, S. \& Butler, E. (2001). Practice Guidelines for Prenatal and Postnatal Outreach in British Columbia, Canada [draft]. Victoria: BC Ministry for Children and Families.

[12] Ministry of Health and Population. (2006). Nepal Demographic and Health Survey. Kathmandu,Nepal: Ministry of Health and Population.

[13] Ministry of Home Affair. (2011). Census of India. India: Ministry of Home Afair.

[14] Nepal Chepang Association. (2009). Annual Progress Report. Kathmandu: Nepal Chepang Associaton.

[15] Sharma, D.P.( 2011). Understanding the Chepangs and Shifting, Dhaulagiri Journal of Sociology and Anthropology vol 5.

[16] Shafqat T., Fayaz S, Rahim R and Saima S. (2015). Knowledge and awareness regarding antenatal care and delivery among pregnant women, department of Obstetrics and Gyanecology. Lady Reading Hospital, Peshwar, Pakistan. Vol.23, no. 2: 88-91

[17] Wetzstein C. (2011). The Washington Times.

[18] World Health Organization. (2011). WHO Health bulletin.

[19] World Health Organization. (2016) . WHO News articles. cited at http://www.who.int/ mediacen tre/news /releases / 2016/antenatalcare-guidelines/en/

Citation: Sunita Shrestha, Rashmi Shrestha, Tej Kumar Shrestha, Erene Shrestha, Sarala Joshi \& Ganesh Paudel, Knowledge and Practice of Antenatal Care among Chepang Women from Chitwan, Nepal.ARC Journal of Public Health and Community Medicine.2018; 3(2):7-11. DOI: dx.doi.org/ 10.20431/2456-0596.0302002

Copyright: (C) 2018 Authors. This is an open-access article distributed under the terms of the Creative Commons Attribution License, which permits unrestricted use, distribution, and reproduction in any medium, provided the original author and source are credited. 